\title{
A MENSURAÇÃO DO RESULTADO DA QUALIDADE EM EMPRESAS BRASILEIRAS*
}

\author{
Roberta Carvalho de Alencar \\ Professora da Universidade de Fortaleza - UNIFOR - CE \\ E-mail: rca@unifor.br \\ Reinaldo Guerreiro \\ Professor Titular do Depto. de Contabilidade e Atuária da FEA - USP \\ E-mail: reiguerr@usp.br
}

\section{RESUMO}

O presente estudo teve como objetivo investigar junto a um grupo seleto de empresas, como elas desenvolvem a mensuração dos resultados decorrentes da implantação dos programas de qualidade. As principais questões de pesquisa colocadas foram: qual a importância que as empresas concedem ao ato de mensurar resultados da qualidade; qual o momento mais propício para efetuar a mensuração desses resultados; quais são as fontes de dados utilizados, e de que forma o resultado é medido. Por meio da pesquisa bibliográfica foi efetuada a análise de duas metodologias de apuração do resultado proporcionado pela qualidade: Custos da Qualidade e Retorno da Qualidade. O estudo empírico foi realizado por meio de questionários junto a 11 empresas listadas no rol das empresas finalistas do Prêmio Nacional de Qualidade desde a sua instituição até o ano de 2001. O estudo de caráter exploratório aponta para a conclusão de que os resultados são calculados apenas parcialmente pelas empresas, tanto no que diz respeito à abrangência do reflexo dos programas nas receitas e custos, quanto no que se refere ao momento de calcular tais resultados. O uso por parte da empresa de medidas indicadoras do efeito potencial da qualidade nas receitas futuras, tais como satisfação e taxa de retenção de clientes e fatia de mercado, demonstra que há consciência da existência e da importância desses efeitos, abrindo o campo para pesquisas de metodologias de mensuração.

Palavras-chave: qualidade, custo da qualidade, resultado da qualidade, retorno da qualidade.

\section{ABSTRACT}

This study aimed to analyze how a selected group of companies measures the results obtained by implanting quality programs. The main research questions were: How important is it for companies to measure quality results? What is the most favorable time for measuring these results? Which data sources are used? How is the result measured? A bibliographic research resulted in two methods for verifying results from quality programs: Quality Costs and Quality Return. An empirical study was carried out by means of questionnaires, which were sent to 11 companies, included on the list of final competitors for the Brazilian National Quality Award since the year of its establishment until 2001. This exploratory study leads to the conclusion that companies only partially calculate their results, with respect to the range of the programs' influence on revenues and costs as well as the time for calculating these results. The companies' use of indices that mark the potential effect of quality on future revenues, such as satisfaction, client retention and market share, demonstrate their awareness of the existence and importance of these effects, making room for research on measuring methods.

Keywords: quality, quality cost, quality result, quality return. 


\section{INTRODUÇÃO}

\subsection{Caracterização do problema de pesquisa}

É crescente a preocupação das empresas com a qualidade de seus produtos e serviços. $O$ aumento da competitividade vem tornando os consumidores cada vez mais exigentes, em termos de qualidade e preço e, portanto, oferecer produtos e serviços de qualidade, hoje, é sinônimo de sobrevivência. A excelência em qualidade é uma premissa fundamental para a permanência da empresa no mercado. Dentro desse cenário são crescentes os investimentos feitos em programas de melhoria de qualidade.

Rust et al. (1994:84) destacam que o movimento em torno da qualidade se tornou popular entre as empresas, em função de evidências empíricas que indicam que qualidade e lucro costumam andar juntos. No entanto, nem sempre melhorias na qualidade levam necessariamente a lucros maiores. Reis in Catelli (1999:561) cita pesquisas que apresentam e discutem esse ponto, demonstrando que, nem sempre, programas de melhoria de qualidade atingem os objetivos propostos, dentre os quais a melhoria da lucratividade. Além de não conduzirem, obrigatoriamente, a uma maior lucratividade, os programas de qualidade não provocam, necessariamente, o mesmo tipo de impacto nos lucros, podendo ora gerar redução de custos, ora provocar aumento de receitas, ou mesmo uma combinação desses dois efeitos.

Assim, como nem todos os esforços de melhoria da qualidade têm o mesmo efeito em termos de aumentar a lealdade dos clientes ou gerar reduções de custos e, dado que os recursos são limitados, para Rust et al. (1994:104) os gastos com a qualidade representam uma clássica decisão de alocação de recursos. Para decidir dentre mais de uma alternativa de alocação dos recursos, é necessário dispor de uma medida de comparação entre as alternativas disponíveis, e é, igualmente, preciso mensurar o efeito potencial de cada decisão. Guerreiro (1989:79) destaca a necessidade de mensuração, afirmando que ela é necessária não somente para expressar objetivos e clarificar alvos, como também para orientar o próprio processo de atingir os alvos, possibilitando o controle e a avaliação. Dessa forma, para que a empresa possa utilizar seus recursos da meIhor maneira possível, torna-se necessário mensurar o efeito desses programas no resultado, antes que os gastos sejam realizados, bem como ao longo da execução do programa.

O movimento em torno da mensuração do resultado proporcionado pelos esforços de melhoria da qualidade não conta com o mesmo número de adeptos que o movimento da qualidade. De acordo com Rust et al. (1994:84), ao mesmo tempo em que acreditam que qualidade e lucros andam juntos, as empresas em geral não apuram os lucros associados a programas de qualidade, pois alguns gerentes acreditam que o valor da qualidade não é possível de ser conhecido, enquanto outros acham que qualidade não deve ser submetida a critérios financeiros. Os autores, no entanto, observam que, quer o impacto sobre o lucro seja medido ou não, o sucesso ou faIha de um programa de qualidade é o seu efeito no lucro da companhia.

Feigenbaum (2001:26) defende a utilidade da mensuração ao declarar: "A chave para a obtenção de uma economia de custos eficaz, com benefícios para a empresa e seus clientes, é reconhecer que o que é medido corretamente é gerenciado corretamente". A literatura contábil tem oferecido algumas alternativas de mensuração dos resultados da qualidade, com maior ênfase no levantamento dos custos da qualidade, embora o efeito da qualidade sobre a receita seja o mais importante dos dois, conforme destacam Juran \& Gryna (1991:35). Embora envolva um certo grau de subjetividade, é inegável a necessidade da mensuração da receita, para que se possa ter uma melhor idéia da dimensão completa da questão da qualidade. Rust et al. apresentam a metodologia chamada $R O Q$ - Return on Quality, que se propõe a determinar parte do efeito da qualidade sobre a receita, no que diz respeito ao aumento da taxa de retenção da clientela já existente.

A despeito das ferramentas existentes, pesquisas apontam que, nem sempre, as empresas estão preocupadas em medir os efeitos da qualidade no resultado. Rust et al. (1994:6) citam pesquisa do U.S. General Accounting Office, em que apenas cinco dos 22 finalistas do prêmio Malcom Baldrige que representariam a elite americana em termos de qualidade, apuravam as reduções de custos decorrentes de seus programas de qualidade. Kannan et al. (2000) 
realizaram pesquisa junto a empresas americanas, a qual evidencia uma preferência por medidas pontuais de desempenho (reclamações, tempo de entrega, devoluções, taxas de rejeitos) em detrimento dos já mencionados custos da qualidade, e da taxa de retenção de clientes, ponto de partida para o cálculo do Retorno da Qualidade (ROQ).

No Brasil, Mattos apud Mattos \& Toledo (1998:314), apurou, em 1996, em pesquisa destinada a diagnosticar o uso de Sistemas de Custo da Qualidade, por empresas com certificação ISO 9000, que $39 \%$ dos respondentes (300 empresas dentre 919 questionários enviados) possuíam Sistemas de Custos da Qualidade (SCQ), implantados ou em implantação e, dentre as $61 \%$ que não possuíam tais sistemas, $83 \%$ tinham planos de implantá-los ou já estavam analisando a implantação de Sistemas de Custo da Qualidade. O panorama levantado aponta para a não mensuração ou mensuração parcial dos resultados dos programas de melhoria de qualidade, no Brasil e no exterior. Diante do exposto, questiona-se se as empresas brasileiras que implantaram programas de melhoria de qualidade estão mensurando os resultados decorrentes dessa iniciativa e, caso positivo, quais critérios de mensuração estão sendo adotados.

\subsection{Aspectos metodológicos}

A hipótese formulada é a de que os resultados, quando mensurados pelas empresas, têm apenas enfocado o aspecto da redução de custos, deixando de apurar o resultado mais significativo da qualidade, segundo o ponto de vista comum de vários autores: a melhoria da rentabilidade por intermédio do crescimento das receitas. Entrevistas exploratórias iniciais, junto a empresas de médio porte, indicaram que essas empresas não utilizam qualquer tipo de medição. A partir dessa constatação e, sendo o objetivo central desta pesquisa saber como as empresas brasileiras estão tratando a questão da qualidade, em termos da mensuração do seu reflexo sobre o resultado, optou-se por um estudo em empresas em que houvesse maior probabilidade de que algum tipo de medição estivesse sendo realizado. O universo de realização da pesquisa foi, então, delimitado: as empresas finalistas e ganhadoras do Prêmio Nacional da Qualidade - PNQ. Esse prêmio, instituído em 1992, tem critérios semeIhantes aos dos mais importantes prêmios internacionais referentes à qualidade.

A opção por este critério deu-se em virtude de dois motivos: (1) as empresas ganhadoras do prêmio representam, dentro de critérios publicamente estabelecidos, a excelência nacional em termos de qualidade, e (2) um dos critérios de pontuação do prêmio é a geração de resultado. As empresas finalistas, embora não tenham chegado a receber 0 prêmio, apresentam, no entanto, características que as apontam como empresas em que a qualidade merece lugar de destaque.

Com esta estratégia, buscou-se verificar, através do estudo das práticas existentes em empresas que representam a excelência nacional em termos de qualidade, um indicativo do comportamento das demais, partindo-se da premissa de que as empresas pesquisadas representam a vanguarda, no que diz respeito à gestão da qualidade e, conseqüentemente, da apuração dos resultados associados a programas de qualidade. Em outras palavras, se as empresas finalistas do Prêmio Nacional da Qualidade não apuram os resultados obtidos pela implantação de programas de qualidade em toda a sua amplitude, as demais empresas, provavelmente, também não o farão. Assim, os achados deste estudo exploratório, embora se refiram à análise de dados obtidos junto $a$ um número muito reduzido de empresas, considerando o universo de empresas brasileiras que tenham algum tipo de programa de qualidade implantado ou em implantação, podem ser utilizados como um indicativo do comportamento das demais empresas.

Agrupando as pesquisas quanto aos seus objetivos, Selltiz et al. (1974:59) identificam três tipos de estudos: formuladores ou exploratórios, descritivos e verificadores de uma hipótese de relação causal entre duas variáveis. A pesquisa em questão, focada no estudo do comportamento de um grupo específico - ganhadores e finalistas do Prêmio Nacional da Qualidade - abordagem que guarda características de um estudo descritivo, tem caráter fundamentalmente exploratório, uma vez que o objetivo principal é prover uma melhor compreensão da questão da medição da qualidade entre as empresas, a partir da qual outros estudos, mais aprofundados, possam ser desenvolvidos. 
As técnicas de levantamento de dados, aqui adotadas, foram: pesquisa bibliográfica e aplicação de questionários. Através da pesquisa bibliográfica, foi realizado um levantamento dos escritos existentes a respeito de Qualidade, como também medições de resultados que pudessem estar associados às iniciativas de qualidade, com vistas a estabelecer o referencial básico dos conhecimentos associados ao tema da pesquisa. $O$ questionário de pesquisa, composto por treze questões, foi remetido, via e-mail, para $26 \mathrm{em}$ presas, a partir de uma lista obtida junto à Fundação para o Prêmio Nacional da Qualidade FPNQ. A lista continha 29 nomes, pertencentes a empresas finalistas e premiadas, desde a instituição do prêmio, em 1992. Alguns nomes se repetem, em mais de um ano, ora como finalistas ora como premiados. Conforme esclarecimentos fornecidos pela assessoria de imprensa daquela Fundação, o nome das empresas agraciadas com o prêmio é tornado público, mas os nomes das empresas classificadas como finalistas são divulgados somente sob expressa autorização de seus dirigentes.

\section{QUALIDADE}

Segundo Juran \& Gryna (1991:11), a palavra qualidade tem dois significados predominantes:

- a qualidade consiste nas características do produto que vão ao encontro das necessidades dos clientes e, dessa forma, proporcionam satisfação em relação ao produto;

- a qualidade é a ausência de falhas.

Para Sakurai (1997:131), o conceito de qualidade pode ser expresso a partir de diferentes pontos de vista:

- grau de conformidade: desse ponto de vista, a qualidade consiste em que o produto seja fabricado de acordo com suas especificações, sem que tenha, necessariamente, de atender às expectativas do cliente;

- adequação ao uso: nesse caso, a qualidade está orientada para o cliente. A qualidade consiste em atender às suas expectativas;

- excelência inata: a qualidade do produto ou serviços deve ter uma superioridade intrínseca, sendo reconhecida até mesmo por aqueles que não consomem aquele produto ou serviço. Um produto de alta qualidade deve ser superior à passagem do tempo, não sofrendo alterações, independentemente da mudança de estilos e gostos.

Já Giffi et al., apud Vergani (1997:30) usam conceitos semelhantes, classificando-os como níveis de qualidade e considerando-os cumulativos, ou seja, cada nível incorpora os anteriores, aumentando, em cada nível, a dificuldade de se atingir a qualidade:

- qualidade de conformidade: A qualidade é conforme as especificações. Produtos se enquadram em limites de tolerância específicos ou serviços atendem a padrões específicos, e produtos são classificados como "Iivres de defeitos";

- qualidade de exigências: A qualidade atende às exigências dos consumidores. $O$ produto (como ele é) percebido e os atributos do serviço atendem às expectativas e preenchem as necessidades dos consumidores;

- qualidade de natureza: A qualidade é tão extraordinária que encanta o consumidor. O produto (como ele é) percebido e os atributos do serviço excedem significativamente às expectativas do consumidor e ele se torna encantado com o valor (percebido).

Garvin (1984:28) observa que a dimensão dada à qualidade por diversos autores decorre de sua formação profissional original. Os autores originários da área de Produção tenderiam a uma visão de Produção, em que qualidade implica em redução de custos, enquanto os procedentes da área de Marketing tenderiam a usar a abordagem do usuário, em que qualidade pode implicar em custos maiores.

Nas diversas definições destacadas, percebese claramente a inexistência de um consenso a respeito do que seja qualidade. São visões parciais, enxergando a questão da qualidade sob um único aspecto, ignorando os demais ou deixandoos em segundo plano. Garvin (1992:57) preconiza que, para um produto atingir realmente a qualidade, deve-se adotar uma abordagem dinâmica desse conceito, dando prioridade a diferentes aspectos, no caminho percorrido desde a concepção do produto até sua colocação no mercado. 


\section{MODELOS DE MENSURAÇÃO DO RESULTADO DA QUALIDADE}

O crescimento da ênfase em qualidade, tanto quanto as mudanças tecnológicas ocorridas no ambiente de produção, gerou a necessidade de um reexame das medidas tradicionais de desempenho, provocando a demanda por um conjunto mais amplo de medidas, (CARR ET AL., 1997:384). O uso de medidas de desempenho, financeiras e não financeiras, para avaliar o desempenho de programas de qualidade, é advogado por diversos autores, tanto quanto medidas que forneçam a visão de resultados a longo prazo. Os modelos apresentados enfocam medidas financeiras de desempenho, objeto da pesquisa desenvolvida neste trabalho.

\subsection{Custos da Qualidade}

Conforme Juran \& Gryna (1991:86), a expressão custos da qualidade pode ter diversos significados: pode referir-se aos custos para se atingir a qualidade, bem como aos custos da área responsável pelo controle de qualidade ou, ainda, aos custos da má qualidade, esses últimos entendidos como custos decorrentes da existência ou da probabilidade de existência de má qualidade. O significado mais aceito para a expressão custos da qualidade tem sido o de custos da má qualidade (JURAN \& GRYNA, 1991:86).

A medição dos custos da qualidade, conforme Rust et al. (1994:93), não tem aceitação universal, apesar da idéia de que melhoria de qualidade resulta em redução de custos. Enquanto Juran e Crosby advogam a medição desses custos, Deming considera a idéia perda de tempo. Na opinião dos autores, essa medição tem o benefício de traduzir problemas de qualidade em termos monetários.

Para Rust et al. (1994:94), "os dois principais objetivos do programa (de medição dos custos da qualidade) são quantificar as conseqüências financeiras de problemas de qualidade e identificar áreas para melhoria da qualidade e redução de custos".

Juran \& Gryna (1991:86-88) identificam cinco dos objetivos que levam as organizações a desenvolver programas de avaliação dos custos da qualidade, classificando os três primeiros objetivos listados como objetivos principais e os dois últimos como objetivos secundários:
- quantificar o problema da qualidade em uma linguagem que tenha impacto sobre a administração superior;

- identificar as principais oportunidades para redução dos custos;

- identificar as oportunidades para diminuir a insatisfação do consumidor e as respectivas ameaças às facilidades de venda;

- expandir os controles orçamentários e de custos;

- estimular o aperfeiçoamento por meio da divulgação.

A classificação mais usada, referente aos custos da qualidade, é de Juran \& Gryna (1991:90): custos das falhas internas, custos das falhas externas, custos de avaliação e custos de prevenção. Os custos das falhas internas estão relacionados à ocorrência de falhas detectadas antes da entrega do produto ou da prestação do serviço ao cliente. Os custos das falhas externas, tanto quanto os custos das falhas internas, relacionam-se às não-conformidades encontradas nos produtos $\mathrm{e}$ serviços, mas diferem quanto ao momento em que são detectados. Denominam-se custos de falhas externas os custos ocorridos em conseqüência de falhas detectadas após a entrega do produto ou prestação do serviço ao cliente.

Para Juran \& Gryna (1991:91-92), custos de avaliação "são os custos incorridos na determinação do grau de conformidade aos requisitos de qualidade". Já os custos de prevenção, "são os custos incorridos para manter em níveis mínimos os custos das falhas e de avaliação". Os custos de falhas são os custos ruins, pois ocorrem em virtude da existência prévia de má qualidade. O objetivo dos programas de melhoria da qualidade é eliminar ou reduzir ao máximo tais custos. Os custos de avaliação e prevenção, também classificados como custos de controle, são os chamados custos bons. São custos incorridos com o objetivo de evitar ou minimizar a ocorrência da má qualidade e, em geral, crescem quando se implanta um programa de melhoria da qualidade.

Shank e Govindarajan (1997:277) observam que nem sempre os custos da qualidade se enquadram perfeitamente em uma categoria ou outra, citando o exemplo do custo de inspeção de matéria-prima, que pode ser visto como um custo de avaliação, se 
enxergado como busca de defeitos, ou como custo de prevenção, em função desse procedimento evitar que a matéria- prima com defeito estrague o processo de produção.

A alocação de custos em uma ou outra categoria, nos casos mencionados, torna-se arbitrária, com os autores destacando que, nesse caso, o mais importante é que as empresas mantenham a coerência, na classificação e ao longo do tempo, para favorecer as análises.

\subsection{Retorno da Qualidade (Return on Quality - ROQ)}

Rust et al. (1994) propõem um modelo de avaliação do retorno da qualidade baseado no estudo do comportamento dos clientes, em relação aos atributos de um produto ou serviço. Com base nesse estudo, pode-se determinar o reflexo desse comportamento nas receitas futuras da companhia. Uma vez descoberto o montante da receita futura, a ela são somadas as economias de custos obtidas pelo programa de qualidade e deduzidos os custos gerados pelo programa de qualidade. O valor presente líquido desse fluxo futuro, representa o retorno sobre o investimento em qualidade. O pressuposto que levou Rust et al. (1994:6) a desenvolverem esse modelo é o de que o investimento em Qualidade, tal qual qualquer outra decisão de alocação de recursos, deve produzir retornos que sejam maiores que os custos, requerendo, portanto, uma metodologia de avaliação dos retornos produzidos.

O retorno, ou seja, o impacto nos lucros proporcionado por um programa de melhoria da qualidade de produtos e processos, faz-se notar em três frentes: redução de custos, aumento da retenção de clientes e atração de novos clientes. Rust et al. (1994) englobam, em seu modelo, os efeitos de redução de custos que deverão ser apurados utilizando-se a metodologia de Custo da Qualidade e o aumento de receitas mediante aumento da retenção de clientes. A terceira vertente, que seria a da atração de novos clientes, é deixada fora do modelo, em função de uma maior dificuldade de medição do seu valor. Para entender melhor o efeito da retenção dos clientes, Rust et al. (1994:84) utilizam a figura de um tanque de água, representando a fatia de mercado detida pela empresa. Os clientes perdidos representam um furo no tanque. Para manter o nível da água (fatia de mercado) estável, a empresa precisa estar constantemente captando novos clientes, que tanto podem ser clientes novos para o mercado como oriundos de seus concorrentes. Para que haja crescimento, a entrada de clientes tem que ser maior que a evasão. Existem duas formas de fazer isso: o marketing agressivo, que busca a atração de novos clientes, ou o marketing defensivo, que privilegia a retenção dos clientes antigos, ou seja, tenciona diminuir o vazamento do tanque. Rust et al. (1994:87) destacam que o enfoque padrão, por muitas décadas, foi o primeiro, mas, nos últimos tempos, o foco na retenção de clientes tem recebido mais atenção, em função do potencial de lucratividade trazido por ele.

Tatikonda \& Tatikonda (1996:2) corroboram essa opinião, quando citam estudos que indicam que um cliente leal traz menor custo para as empresas, exemplificando que uma certa empresa de auto-serviço descobriu que o lucro proporcionado por um cliente, no quarto ano, é mais do que o triplo do lucro proporcionado pelo mesmo cliente no primeiro ano de relacionamento. $\mathrm{O}$ aumento da lealdade dos clientes, por sua vez, mantém estreita relação com o grau de sua satisfação. Segundo Godfrey, citado por Tatikonda \& Tatikonda (1996:2), a Xerox Company descobriu que um cliente muito satisfeito torna-se seis ou sete vezes mais propenso a voltar a comprar seus produtos que um cliente satisfeito.

Para Rust et al. (1994:41), satisfação é uma resposta emocional, influenciada não só pela qualidade percebida pelo usuário, mas, também, pelo seu nível de expectativa acerca do produto ou serviço. Existem diferentes níveis de satisfação. Esses tais níveis influenciam o comportamento do cliente, em termos de intenção de recompra, propaganda positiva boca-a-boca, etc. O início do estudo do Retorno da Qualidade se dá com a realização de pesquisa entre os clientes da empresa, com o objetivo de levantar de que maneira os vários aspectos do serviço prestado pela companhia podem alcançar as suas expectativas e a probabilidade de continuarem leais à empresa durante os próximos períodos (RUST ET AL., 1994:107). Com base nesses dados, pode-se chegar, por meio de métodos estatísticos, a relacionar satisfação e retenção. Rust et al. (1994:107) ressaltam a importância desse passo, declarando que: 
"Determinar o relacionamento entre os níveis de satisfação dos clientes e retenção é especialmente importante na escolha de áreas para atenção. As áreas mais importantes são aquelas que levam os clientes a deixarem a empresa ou permanecerem leais, não necessariamente aquelas que recebem o maior número de reclamações ou aquelas para as quais a satisfação é avaliada como a pior”.

Outra etapa necessária à determinação do retorno da qualidade é estabelecer, para cada dimensão ou processo do negócio estudado, o impacto relacionado à alteração no nível de satisfação do cliente. Essa importância relativa é dada por escores que vão de 0 a 100 e, quanto maior o escore, tanto maior o impacto. Para entender o relacionamento existente entre a fatia de mercado e a taxa de retenção dos clientes, a empresa tem que compreender a dinâmica do mercado. Para tanto, é necessário conhecer (Rust et al., 1994:108):

- a extensão das trocas de marcas/empresas pelos clientes no mercado;

- a taxa de entrada de novos clientes no mercado;

- o percentual de clientes novos para o mercado, que poderão ser atraídos para a empresa;

- o percentual de clientes que deixam o mercado.

Rust et al. (1994:108) afirmam que, uma vez a dinâmica do mercado tenha sido entendida, fica relativamente fácil ligar a fatia de mercado às receitas. Para tanto, são necessárias duas informações adicionais: o tamanho do mercado e a lucratividade média por cliente no segmento em estudo: "Multiplicando a fatia de mercado pelo número de clientes existentes no mercado pela média de lucro por cliente é possível converter previsões de fatia de mercado em dólares". A partir do entendimento das ligações entre a satisfação dos clientes e as receitas, é possível estimar o reflexo de cada iniciativa de qualidade no resultado, juntando-se as informações sobre os custos associados a cada projeto.

\section{APRESENTAÇÃO E ANÁLISE DOS RESULTADOS}

Uma vez considerados os diversos aspectos relacionados à qualidade e levantados dois macromodelos de mensuração do resultado da qualidade, um com foco no custo e outro abrangendo também a receita, buscou-se identificar o estado de coisas na realidade empresarial brasileira. Com esse foco, questionários foram encaminhados a empresas passíveis de serem classificadas como topo de linha em termos de gestão da qualidade, no caso as empresas ganhadoras e finalistas do Prêmio Nacional da Qualidade-PNQ, no período de 1992 a 2001. Cabe notar que o Prêmio Nacional de Qualidade visa avaliar a gestão empresarial e não a qualidade de produtos, processos ou serviços.

O questionário abrangeu aspectos relacionados aos motivos pelos quais as empresas optaram por implantar programas de melhoria de qualidade; até que ponto os objetivos iniciais foram atingidos; os reflexos observados em algumas variáveis relacionadas à qualidade e que devem refletir no resultado final, tais como volume de vendas, fatia de mercado, gastos com publicidade, treinamento e outros; a importância dada pelas empresas à mensuração do resultado; as fontes de dados e as ferramentas mais utilizadas nessa mensuração. Onze empresas das vinte e seis para as quais foram remetidos questionários deram retorno, representando $42 \%$ da mostra.

Dentre as empresas pesquisadas, $18 \%$ implantaram programas de qualidade entre 1970 e 1979 , $46 \%$ entre 1980 e 1989, 27\% entre 1990 e 1995 e $9 \%$ após 1996 . O índice de $64 \%$, de empresas que iniciaram a implantação de programas de qualidade, antes de 1990, indica que as empresas se inserem no grupo pioneiro em programas de qualidade no Brasil. Pode-se chegar a essa conclusão, analisando-se esses dados conjuntamente com a cronologia de fatos marcantes que compõem o histórico do desenvolvimento de uma cultura empresarial voltada para a qualidade no Brasil, organizado por Bido (1999:14-15).

Observa-se, na análise conjunta das informações fornecidas com o histórico do desenvolvimento da qualidade no Brasil, que sete delas, representando $64 \%$ das 11 empresas pesquisadas, iniciaram implantação de programas de qualidade no período que antecedeu à concessão do primeiro certificado ISO 9000, e da criação do Prêmio Nacional da Qualidade. Das sete empresas destacadas, duas implantaram programas de qualidade no período em que o movimento estava apenas nascendo no Brasil (19701979), e cinco no período seguinte (1980-1989), no qual a cultura começou a ser implantada no meio 
acadêmico e empresarial, por meio da troca de idéias com alguns dos maiores expoentes da qualidade (JURAN, CROSBY, ISHIKAWA E DEMING), que visitaram o Brasil promovendo palestras e da criação de cursos de pós-graduação.

Na década que se seguiu, 1990 a 2000, houve efetiva expansão da qualidade no Brasil. De acordo com Castro (2000:32), a abertura da economia ao mercado internacional resultou numa maior exposição às leis de mercado, obrigando as empresas brasileiras a buscarem soluções no sentido de reduzir desperdícios, racionalizar processos, modernizar e aperfeiçoar a gestão empresarial, tornando o ano de 1990 o marco inicial de um movimento amplo e consistente pela qualidade, no Brasil. Castro (2000:32) apresenta, ainda, algumas evidências desse rápido crescimento, citando que a taxa média anual da Produtividade Industrial, segundo a OCDE, passou de $-0,5 \%$, no período de 1985 a 1990 , para $+8,3 \%$, no período de 1990 a 1995; e o número de empresas certificadas pelas normas da Série ISO, saltou de 35 até 1991, para 948 em 1995, chegando a 5285 em 1999.

Três empresas, correspondendo a $27 \%$ do total, iniciaram a implantação entre 1990 e 1995, e apenas uma após 1996. Essa constatação reforça a condição deste estudo, respeitado seu caráter exploratório, de fornecer uma boa contribuição ao entendimento do comportamento das empresas brasileiras no que diz respeito à mensuração do resultado financeiro dos programas de melhoria de qualidade, uma vez que as empresas pesquisadas, além de integrar um grupo com reconhecida superioridade em termos de gestão da qualidade, foram, também, pioneiras na implantação da qualidade.

Procurou-se identificar quais motivos levaram as empresas pesquisadas a implantar programas de melhoria de qualidade. Foram elencados nove motivos, encontrados na literatura pertinente ao assunto ou sugeridos por profissionais contactados durante as entrevistas exploratórias que subsidiaram a elaboração do questionário. Os motivos com maior índice de respostas positivas (concordo/concordo totalmente) foram os de reduzir custos $(91 \%)$, tornar o produto superior ao da concorrência $(82 \%)$, abertura de mercados mais exigentes $(82 \%)$ e ampliar a fatia de mercado (82\%), demonstrando a existência de um ambiente competitivo, que estimula as empresas a investirem em melhoria de qualidade. Corroborando essa idéia, a possibilidade de elevar preços, a partir de um aumento da qualidade, foi o quesito com maior percentual de respostas negativas, tendo $82 \%$ respondido que discordavam ou discordavam totalmente.

Em relação aos mesmos motivos, foi perguntado às empresas até que ponto as expectativas existentes, ao se implantar programas de melhoria de qualidade, foram atendidas. Dentre as respostas obtidas, merecem destaque: a redução de custos e o reconhecimento de excelência em qualidade. Embora permaneça com o maior índice de respostas positivas, no quesito redução de custos o efeito é menor do que o esperado, uma vez que $73 \%$ das empresas concordaram, totalmente, com a afirmação de que reduzir custos foi um dos motivos que as levaram à implantação de programas de qualidade e, quando perguntadas acerca do atendimento a esse objetivo, o percentual caiu para $55 \%$.

Em relação ao reconhecimento de excelência em qualidade, embora esse não seja um fator dos mais citados entre os motivos, é um reflexo que se fez sentir em $100 \%$ das empresas. Naturalmente, em termos da amostra adotada, a pesquisa é tendenciosa, pois as empresas pesquisadas foram escolhidas exatamente por terem recebido reconhecimento público por sua excelência em qualidade.

Uma outra questão levantou o reflexo da qualidade em variáveis que afetam, direta ou indiretamente, os resultados, a saber: fatia de mercado, vendas, custos de produção, giro de clientes, giro de empregados, gastos com publicidade e gastos com treinamento. No que diz respeito à fatia de mercado, $80 \%$ das empresas responderam que obtiveram crescimento; $60 \%$ obtiveram crescimento da fatia de mercado superior a $10 \%$. As demais reportaram ter mantido a fatia de mercado. No quesito vendas, o comportamento relatado foi idêntico. Todas as empresas participantes da pesquisa deram para o quesito fatia de mercado e volume de vendas a mesma resposta, levando a crer que pode ter havido uma confusão no entendimento a respeito dos dois conceitos, tratados como se fossem a mesma coisa.

Já o giro de clientes, ou seja, o percentual de clientes perdidos, manteve-se estável em $60 \%$ das empresas pesquisadas. A partir do cruzamento dessas respostas com o relato de aumento nas vendas 
e na fatia de mercado, pode-se inferir que o aumento se deu pela conquista de novos clientes e não pela retenção dos antigos. O reflexo reportado pelas empresas a respeito da rotatividade da clientela reforça a idéia de que têm priorizado, efetivamente, a qualidade de conformidade, voltada para a redução de custos, e com maior foco para os seus processos internos. Com isso, as iniciativas pouco têm resultado em uma maior fidelidade por parte dos clientes, reportada por diversos autores, dentre eles Rust et al. (1994) e Tatikonda \& Tatikonda (1996), como multiplicadores do resultado da empresa. Os gastos com publicidade mantiveram-se estáveis em $60 \%$, e em $40 \%$ tais gastos sofreram crescimento. Uma hipótese a construir, partindo-se dessa informação, é a de que os gastos com publicidade se mantiveram estáveis/em alta, em razão do esforço que a empresa precisa fazer para captar novos clientes, uma vez que não reduziu a taxa de perda dos clientes ativos.

No que diz respeito aos custos de produção, em $70 \%$ das empresas ocorreu uma redução superior a $10 \%$. Em $20 \%$, os custos permaneceram estáveis e em apenas $10 \%$ ocorreu uma elevação nos custos, o que se mostra coerente com o objetivo de redução de custos aceito pela maioria das empresas, na questão dois.

Em relação à rotatividade de empregados, a redução ocorreu em $50 \%$ das empresas, enquanto nas outras $50 \%$ manteve-se estável. O reflexo do programa de qualidade na rotatividade dos empregados apresenta-se compatível com as conclusões do estudo de Bianco \& Salerno (2001), conduzido, inicialmente, junto a 11 empresas de manufatura de grande porte, líderes em seus ramos de atividade e, posteriormente, com o objetivo de confirmar as constatações da primeira pesquisa, junto a duas empresas às quais foi outorgado o Prêmio Nacional da Qualidade. Uma das conclusões a que chegaram os citados pesquisadores foi que, no que diz respeito à política de gestão de recursos humanos, essa pouco mudou com a implantação do TQM (BIANCO \& SALERNO, 2001:64). Observa-se que, apesar de os programas de qualidade colocarem como pressuposto o envolvimento e participação do pessoal, e também do discurso fervoroso de Deming justificando que só é possível implantar qualidade em um ambiente em que as pessoas se sintam seguras, o reflexo dos programas de qualidade na rotatividade do pessoal não implicou em mudança, em metade das empresas pesquisadas.
Já os gastos com capacitação e treinamento cresceram em $80 \%$ das empresas que responderam ao questionário, permanecendo estável nas demais. 0 aumento dos gastos com treinamento é algo esperado, quando se trata de programas de qualidade, já que a base desse processo são as pessoas. Esses custos, se corretamente aplicados, contribuem para uma troca compensatória entre custos de prevenção e custos de falhas no processo ou no produto.

Perguntadas acerca do grau de importância atribuído à mensuração do resultado da qualidade, na questão sete, $89,9 \%$ das empresas consideraram importante ou muito importante realizar a mensuração. Dentre as razões apresentadas para a mensuração do resultado dos programas de melhoria da qualidade, as afirmativas: identificar as oportunidades de diminuir a insatisfação do consumidor, focar esforços de melhoria da qualidade nos itens de maior custo, alertar para o aparecimento de novos problemas de qualidade e focar esforços de melhoria da qualidade nos itens que mais afetam a satisfação dos clientes, obtiveram $100 \%$ de aprovação, considerando-se as respostas concordo e concordo totalmente. Dentre as respostas com 100\% de aprovação, apenas uma, focar esforços de melhoria de qualidade nos itens que mais afetam a satisfação dos clientes, aponta para uma possível dimensão da qualidade voltada para fora, adotando qualidade na abordagem do cliente ou do valor.

As demais respostas estão, fortemente, voltadas para a qualidade de conformidade e, conseqüentemente, controle de custos; integram as razões citadas por Juran \& Gryna (1991), que justificam o cálculo dos custos da qualidade. A forte visão da qualidade como conformidade, ou seja, a abordagem baseada na produção, é reforçada pelo número de Engenheiros dentre os responsáveis pela área ou função de qualidade dentre as empresas pesquisadas.

O menor nível de aceitação (respostas Discordo/Discordo totalmente) ficou com as razões relacionadas à avaliação do programa ou da área responsável pela gestão de qualidade, e com a determinação do ponto ótimo da alocação de recursos em custos de prevenção. Dentre as razões expostas, no entanto, a única a que a maioria dos respondentes manifestou-se contrária foi a de avaliar o desempenho da área responsável pela gestão da qualidade. Conforme pode ser constatado, as empresas pesquisadas aceitam parcial- 
mente a idéia de se efetuar a mensuração e avaliação de resultados dos programas de qualidade, bem como o estudo de níveis de investimentos em qualidade necessários. Por outro lado, a pesquisa indica que as empresas não são favoráveis à avaliação de resultados da área responsável pela qualidade através de medidas financeiras.

Esse posicionamento, provavelmente, tem explicação no tipo de medida financeira mais comum do resultado da qualidade, qual seja o cálculo do Custo da Qualidade. A contribuição da qualidade para a melhoria do resultado é evidenciada por meio da redução de custos e seus reflexos se fazem sentir a longo prazo, uma vez que, no período inicial, os custos com prevenção e avaliação aumentam, e a queda nos custos com falhas só ocorre após um certo lapso de tempo, podendo ocorrer, a curto prazo, uma elevação de custos. Esse fato é destacado por Shank \& Govindarajan (1997), que argumentam com o uso de medidas não financeiras juntamente às financeiras, para avaliar os resultados da qualidade. Dessa forma, os reflexos das decisões tomadas e das ações empreendidas pela área de qualidade estendem-se por diversos períodos posteriores e, por um provável desconhecimento de medidas que evidenciem, na data presente, os reflexos de longo prazo de uma decisão tomada, os respondentes recusaram a idéia de utilizar as informações acerca de resultado da qualidade para avaliar a área.

Além das respostas já comentadas, também foram objeto de estudo as seguintes: conhecer o quanto a empresa está perdendo por falta de qualidade (91\% de aceitação), determinar a viabilidade econômica de um projeto de melhoria de qualidade $(73 \%$ de aceitação), focar esforços de melhoria da qualidade nos itens que mais afetam a receita $(82 \%$ de respostas positivas) e priorizar alocação de recursos (82\% de concordância), todas voltadas para decisões relacionadas ao período que antecede à implantação do programa de qualidade.

Quanto à fase do processo em que os resultados deverão ser mensurados, a maioria das empresas concorda que a mensuração deva ser feita em todas as fases do processo, com graus diferenciados de concordância. A totalidade das empresas concorda com a necessidade de mensurar o resultado antes da implantação do programa, mas esse número cai, quando se trata de mensurar resultados durante ou após a implantação do programa, levando à não verificação de se os resultados projetados estão sendo efetivamente atingidos.

Quanto às ferramentas utilizadas para mensurar os resultados proporcionados pelos programas de qualidade, questionou-se a freqüência com que cada ferramenta era utilizada.O primeiro grupo de ferramentas listadas referia-se à classificação mais comum dos custos da qualidade, a saber:

- apuração do custo de prevenção e avaliação;

- apuração do custo com falhas internas;

- apuração do custo com falhas externas.

Em relação aos chamados Custos da Qualidade (Prevenção, Avaliação, Falhas Internas e Falhas Externas) verificou-se o uso mais freqüente do custo de falhas internas e externas, tendo $64 \%$ dos respondentes indicado que se utilizam dessa ferramenta, freqüentemente ou sempre. Já em relação aos custos com prevenção e avaliação, a quantidade de empresas que se utilizam dessa informação, com maior freqüência, cai para $46 \%$. Dois pontos merecem destaque em relação à utilização não uniforme do registro dos custos da qualidade de falhas e prevenção e avaliação, por parte das empresas. O primeiro deles diz respeito ao fato de os custos com prevenção e avaliação estarem sendo apurados com menor freqüência do que os custos com falhas, já que esses custos são relatados na literatura consultada como mais objetivamente mensuráveis. O outro ponto diz respeito à impossibilidade, em algumas empresas, de realizar acompanhamento da evolução dos custos da qualidade e da economia por eles proporcionada, já que não há como contrapor custos de falhas versus custos de controle. Visando esclarecer até que ponto os custos com falhas estavam sendo efetivamente apurados foram incluídos, a título de controle, na questão, alguns indicadores pontuais de custos com falhas internas e externas, a saber:

a) Falhas externas:

- Percentual de devoluções de vendas e cancelamentos de pedidos;

- Custos com garantia.

b) Falhas internas:

- Taxas/Custos de sucateamento;

- Taxas/Custos de retrabalho;

- Custo financeiro da manutenção de estoques de segurança. 
As respostas relativas aos custos com falhas externas, destacados, confirmam a sua utilização por parte das empresas, pelo menos no que se refere à parte objetivamente mensurável de tais custos. Apurou-se que $64 \%$ das empresas apuram o percentual de devolução de vendas e cancelamento de pedidos, freqüentemente ou sempre, e $82 \%$ o fazem para custos com garantia. Observase, também, o percentual de $18 \%$ para a devolução de vendas e cancelamento de pedidos, e o de $9 \%$ para custos com garantia, de empresas que nunca efetuam esses cálculos, evidenciando que existem outras modalidades de custos de falhas externas sendo calculados pelas empresas, uma vez que nenhuma delas informou nunca haver apurado custo de falhas externas.

A efetiva apuração dos custos com falhas internas foi testada a partir da indagação sobre a freqüência de utilização do cálculo de taxas ou custos de retrabalho, taxas ou custos de sucateamento e custo financeiro de estoques de segurança. Embora 64\% das empresas apurem com freqüência os custos com falhas internas, no que diz respeito a custos com retrabalho, somente $45 \%$ apuram esse valor, freqüentemente ou sempre.

Já no que se refere aos custos ou taxas de sucateamento, o percentual de empresas que apuram esse valor, freqüentemente ou sempre, aumenta para $55 \%$, ficando, no entanto, ainda aquém do percentual informado pelas empresas de utilização do custo de falhas internas. Uma surpresa agradável fica por conta da mensuração do custo financeiro dos estoques de segurança, um dos custos escondidos abordados na literatura e mensurados, com freqüência, por $73 \%$ das empresas.

Um outro conjunto de itens do questionário destaca o uso de ferramentas relacionadas ao cálculo do impacto da qualidade em termos do acréscimo de receitas, o que pode sinalizar um ponto de partida para a mensuração do resultado da qualidade, de forma mais abrangente:

- fluxo de caixa descontado das receitas adicionais previstas em função do programa de melhoria da qualidade;

- pesquisa de satisfação dos clientes, atual e projetada;

- percentual da fatia de mercado;

- percentual de retenção dos clientes.
A pesquisa indicou baixo uso do fluxo de caixa descontado das receitas adicionais previstas, preconizado pelo modelo do Retorno da Qualidade. Das empresas respondentes, apenas $27 \%$ utilizam essa ferramenta, freqüentemente ou sempre. No entanto, os demais tipos de fontes de dados, voltados ao estudo da reação do mercado à qualidade dos produtos e serviços, são utilizados em larga escala. Esses dados, usados em conjunto, podem levar ao cálculo do retorno da qualidade destacado no tópico três.

O primeiro deles é o percentual da fatia de mercado, acompanhado sempre por $64 \%$ das empresas, freqüentemente por $18 \%$ delas e, medianamente, pelas $18 \%$ restantes, não havendo registro de empresas que nunca acompanham ou que pouco acompanham a evolução dessa informação. Já a pesquisa de satisfação dos clientes sempre é objeto de verificação por parte de $91 \%$ das empresas pesquisadas.

Segundo Nagar \& Rajan (2001:496), diversas pesquisas revelam que mudanças nas medidas de satisfação dos clientes têm tido pouco resultado como indicador de vendas futuras, destacando, no entanto, que isso talvez se deva a problemas com as medidas de satisfação. Uma vez que a autoridade para comprar, nas empresas clientes, está espalhada entre diversos empregados e que cada um pode ter diferente opinião acerca do fornecedor, as medidas de satisfação, para, efetivamente, refletirem a realidade, deveriam computar a satisfação de cada um desses empregados, ponderada pela sua autoridade para comprar.

Por último, o percentual de retenção de clientes é ferramenta utilizada com alta freqüência em $82 \%$ das empresas. Em que pese o acompanhamento dessa informação, ela parece ter tido pouca repercussão dentro das empresas, uma vez que a implantação dos programas de qualidade nas empresas pesquisadas pouco refletiu em alteração do turnover de clientes.

Quanto às fontes de dados utilizadas, todas as fontes citadas têm alto índice de utilização. Um destaque deve ser feito ao percentual de respostas indicando um percentual de $55 \%$ de empresas que utilizam, sempre, a pesquisa de mercado como fonte e $18 \%$ que a utilizam freqüentemente, totalizando $73 \%$. Essa resposta parece estar em desacordo com os $91 \%$ que indicaram pesquisar sempre a satisfação de clientes. 
A questão que solicitava a distribuição percentual dos custos da qualidade, foi objeto de resposta por parte de apenas duas empresas, sendo que uma delas, efetivamente, preencheu o formulário, enquanto a outra observou que a empresa não calcula "custos da qualidade", por entender que a qualidade deve estar intrinsecamente ligada a tudo o que é feito. Uma vez que $46 \%$ das empresas indicou calcular custos de prevenção e avaliação, e 64\% custos de falhas, a inferência que se pode fazer é a de que a maioria das empresas não respondeu a esse quesito por considerar que se tratava de informação considerada estratégica e, portanto, não sujeita a divulgação.

Por fim, inquiria-se o grau de satisfação acerca dos resultados obtidos com o programa de melhoria da qualidade. Cem por cento das empresas responderam que consideravam o resultado satisfatório. Questiona-se até que ponto os resultados relatados como satisfatórios nesse item são resultados financeiros, já que poucas empresas concordaram com a possibilidade de utilizar a medição do resultado para avaliação de desempenho de programas e áreas responsáveis pela qualidade.

\section{CONSIDERAÇÕES FINAIS}

A pesquisa realizada com empresas que estão na vanguarda nacional, em termos de qualidade, mostra que, a despeito da visão direcionada fortemente para avaliação dos reflexos em termos de fatia de mercado, satisfação e retenção dos clientes, o objetivo mais presente entre as empresas, no que se refere à implantação de programas de qualidade, ainda é o da redução de custos.

As empresas pesquisadas reconhecem a importância de mensurar o resultado decorrente dos programas de melhoria da qualidade e realizam essa mensuração em todas as fases do processo (antes, durante e após a implantação do programa), com maior ênfase para o período que antecede à implantação. Coerentemente à constatação anterior, observa-se que a preocupação das empresas em apurar o resultado da qualidade está muito mais relacionada ao direcionamento de ações do que ao controle e avaliação de desempenho de projetos e áreas, dificultando a correção de rumos. Uma vez que nem sempre os resultados são usados para acompanhar tal desempenho, pode-se questionar até que ponto as projeções efetuadas traduziram resultados realmente ocorridos.
Na mensuração do resultado, o Custo da Qualidade é utilizado pela maioria das empresas; poucas usam o fluxo descontado das receitas adicionais previstas, confirmando a hipótese de pesquisa, de que, ao mensurar o resultado da qualidade, as empresas não estariam enxergando toda a amplitude da questão e, especificamente, não estariam apurando o reflexo da qualidade sobre a receita.

No entanto, a alta utilização de medidas voltadas à avaliação dos reflexos da qualidade em fatores diretamente relacionados às receitas futuras, tais como percentual da fatia de mercado, satisfação dos clientes e retenção dos clientes, evidencia a existência de uma consciência, dentre aqueles encarregados de gerenciar a qualidade, de que o reflexo da qualidade também se faz sentir no campo das receitas.

A preocupação das empresas com o fato, demonstra a existência de um campo aberto para a pesquisa de metodologias que favoreçam o cálculo de medidas financeiras do resultado da qualidade, que abranjam não só os aspectos relativos à redução de custos, mas também a elevação de receitas.

Durante a realização deste estudo, surgiram diversas questões que podem ser fruto de futuras abordagens:

- verificou-se a escassez de literatura abordando modelos de mensuração do reflexo da qualidade nas receitas futuras, enfocando o aspecto da redução do potencial de perdas dos clientes atuais e conquista de novos clientes, o que abre possibilidade para pesquisas destinadas a elaborar modelos teóricos de mensuração;

- o estudo demonstrou que deve ser incentivada a aplicação da metodologia de retorno da qualidade, proposta por Rust et al. a um estudo de caso, com o objetivo de melhor explorar as potencialidades e limitações desse modelo;

- a análise dos reflexos dos programas de qualidade foi levantada a partir de informações recebidas das empresas, que podem muito bem ter sido simplesmente baseadas no emocional das pessoas que responderam à pesquisa. Estudos posteriores poderiam observar o desempenho econômico-financeiro de empresas de um mesmo setor de atividade, verificando o reflexo nas empresas que implantaram e nas que não implantaram programas de melhoria de qualidade. 


\section{REFERÊNCIAS BIBLIOGRÁFICAS}

BIANCO, Mônica de F. e SALERNO, Mário S. Como opera o TQM e o que muda nas empresas? Um estudo a partir de empresas líderes no Brasil. Gestão \& Produção v.8, n.1, p. 56-67, abr 2001.

BIDO, Diógenes de Souza. Implementação de sistemas da qualidade para a busca de certificação em pequenas e médias empresas do ramo automotivo. São Paulo: 1999. Dissertação de Mestrado - Faculdade de Economia, Administração e Contabilidade da Universidade de São Paulo-FEA-USP.

CARR, Shirley; MARK, I.T. e NEEDHAM, Jane E. Differences in strategy, quality management practices and performance reporting systems between ISO accredited and non-ISO accredited companies. Management Accounting Research, 1997, 8, 383-403.

CASTRO, Orlando E. A qualidade de 1990 a 2000. Revista Banas Qualidade.Vol 10. Número 100. Setembro/2000. p.32-36)

CATELLI, Armando (Coordenador). Controladoria: uma abordagem da gestão econômica - GECON. São Paulo: Atlas, 1999.

CROSBY, Philip B. Qualidade é investimento $3^{\mathrm{a}}$ Ed Rio de Janeiro: José Olimpio, 1988.

DEMING, W. Eduards. Qualidade: a revolução da administração. Tradução de: Out of the crisis, realizada por Clave Comunicações e Recursos Humanos. Rio de Janeiro: Marques Saraiva, 1990.

GARVIN, David. What does "Product Quality" really mean? Sloan Management Review Fall 1984 p.25-43

Gerenciando a qualidade: a visão estratégica e competitiva. Tradução de : Managing Quality. Rio de Janeiro: Qualitymark, 1992

GUERREIRO, Reinaldo. Modelo conceitual de sistema de informação de gestão econômica: uma contribuição à teoria da comunicação da contabilidade. Tese (Doutorado em Controladoria e Contabilidade) - FEA/USP. São Paulo: Universidade de São Paulo, 1989.

JURAN, J. M. e GRYNA, Frank M. Juran controle da qualidade handbook: conceitos, políticas e filosofia da qualidade. Volume I.4 Edição São Paulo: Makron Books do Brasil/McGraw Hill, 1991.

KANNAN, Vijay R; KEAH-CHOON, Tan; HANDFIELD, Robert B; e GHOSH, Soumen. Quality in the boardroom and on the shop floor: a survey of contemporary quality practice. Production and Inventory Management Journal Fourth Quarter, 2000.

MATTOS, Jarbas César de e TOLEDO, José Carlos. Custos da Qualidade: Diagnóstico nas empresas com certificação ISO 9000. Gestão \& Produção v.5, n.3, p. 312-324, dez 1998.

NAGAR, Venky e RAJAN, Madhav V. The revenue implications of financial and operational measures of product quality. The Accounting Review. v.76, n.4, p.495-513. Outubro/2001.

RUST, Roland T. ZAHORIK, Anthony J. e KEININGHAM, Timothy L. Return on quality: measuring the financial impact of your company's quest for quality. Chigago: Probus Publishing Company, 1994.

SAKURAI, Michiharu. Gerenciamento integrado de custos. Tradução Adalberto Ferreira das Neves. Revisão Técnica: Eliseu Martins São Paulo: Atlas,1997.

SELLTIZ, Claire; JAHODA, Marie; DEUTSCH, Morton; e COOK, Stuart W. Métodos de pesquisa nas relações sociais. Edição revista e nova tradução de Dante Moreira Leite. São Paulo: EPU, 1974.

SHANK, John K. e GOVINDARAJAN, Vijay. A revolução dos custos: como reinventar e redefinir sua estratégia de custos para vencer em mercados crescentemente competitivos. Rio de Janeiro: Campus, 1997.

TATIKONDA, Lakshmi U. e TATIKONDA, Rao J. Measuring and reporting the cost of quality. Production and Inventory Management Journal, Second Quarter, 1996, p.1-7.

VERGANI, Marcos Mei. Contribuição para o estudo da avaliação econômico-financeira de programas de melhoria de qualidade. Dissertação de Mestrado São Paulo: USP, 1997.

\section{BIBLIOGRAFIA COMPLEMENTAR}

BANAS QUALIDADE. Sistema Brasileiro da Qualidade. Edição Especial. Separata da Revista Banas Qualidade n 89.

FEIGENBAUM, Armand V. Total quality control. $3^{\text {rd }}$ Edition New York: McGraw-Hill, 1983

How to manage for quality in today's economy. Quality Progress May 2001 p.26-27.

MARTINS, Gilberto. Manual para elaboração de monografias e dissertações. $2^{a}$ Ed. São Paulo: Atlas, 2000.

NOTA:

Endereço dos Autores:

ROBERTA CARVALHO DE ALENCAR

Universidade de Fortaleza

Av. Washington Soares, 1321 - CX. POSTAL 1258

Fortaleza - CE

60811-905
MARTINS, Gilberto de Andrade e LINTZ, Alexandre. Guia para elaboração de monografias e trabalhos de conclusão de curso. São Paulo: Atlas, 2000.

McNAIR, Carol J. Maximizando o lucro final: alto desempenho em todas as linhas do "lucros e perdas". Título do original: The profit potential :taking high performance to the bottom line. São Paulo: Makron Books, 2000.
REINALDO GUERREIRO

Universidade de São Paulo - Depto. de Contabilidade e Atuária Av. Prof. Luciano Gualberto, 908

Butantã - São Paulo - SP

05508-900 


\section{ANEXO: QUESTIONÁRIO DE PESQUISA

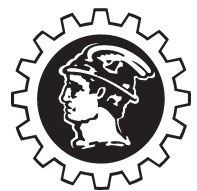 \\ UNIVERSIDADE DE SÃO PAULO \\ FACULDADE DE ECONOMIA, ADMINISTRAÇÃO E CONTABILIDADE}

\section{Apresentação}

O presente questionário tem por objetivo realizar um levantamento das práticas de mensuração dos resultados decorrentes de programas de melhoria da qualidade junto às empresas finalistas $\mathrm{e}$ ganhadoras do Prêmio Nacional da Qualidade - PNQ.

A pesquisa em questão destina-se à elaboração da dissertação de mestrado da aluna do Curso de Pós-Graduação em Controladoria e Contabilidade da USP, Sra. Roberta Carvalho de Alencar, sob a orientação do Prof. Dr. Reinaldo Guerreiro.

Enquadram-se na expressão "Programa de melhoria da qualidade", para fins desta pesquisa, todas as ações destinadas a proporcionar a melhoria de produtos e/ou processos, independentemente da ferramenta utilizada.

Os dados levantados por meio deste questionário, serão utilizados e citados de forma agregada, preservando-se o sigilo das informações.

As dúvidas por acaso surgidas no preenchimento do questionário poderão ser solucionadas por meio do e-mail: robertaalencar@uol.com.br

\section{Programas de Melhoria da Qualidade}

1) Quando a empresa iniciou a implantação de programas de melhoria da qualidade?
( ) Antes de 1970
( ) Entre 1970 e 1979
( ) Entre 1980 e 1989
( ) Entre 1990 e 1995
( ) Após 1996

2) Atribua notas de 1 a 5 para os motivos que levaram a empresa à decisão de implantar programas de melhoria da qualidade.

$5=$ concordo totalmente; $4=$ concordo; $3=$ não concordo nem discordo; $2=$ discordo; $1=$ discordo totalmente

( ) Possibilidade de redução de custos via eliminação de desperdícios, perdas e retrabalhos

( ) Tornar o produto e/ou serviço superior ao da concorrência

( ) Orgulho do grupo proprietário da empresa em que esta seja reconhecida como um centro de excelência

( ) Abertura de novos mercados, mais exigentes em termos de qualidade

( ) Manutenção da fatia de mercado

( ) Ampliação da fatia de mercado

( ) Possibilidade de elevar preços a partir de uma qualidade maior

( ) Exigência de clientes do mercado interno

( ) Exigência de clientes do mercado externo

Revista Contabilidade \& Finanças - USP, São Paulo, Edição Especial, p. 07 - 23, 30 junho 2004 
3) O programa correspondeu às expectativas em relação aos motivos acima citados? Atribua notas de 1 a 5 em sua resposta, se a empresa obteve:

$5=$ concordo totalmente; $4=$ concordo; $3=$ não concordo nem discordo ; 2 = discordo ; $1=$ discordo totalmente

( ) Redução de custos via eliminação de desperdícios, perdas e retrabalhos

( ) Produto e/ou serviço superior ao da concorrência

( ) Reconhecimento como um centro de excelência

( ) Abertura de novos mercados, mais exigentes em termos de qualidade

( ) Manutenção da fatia de mercado

( ) Ampliação da fatia de mercado

( ) Elevação de preços a partir de uma qualidade maior

( ) Atendimento da exigência de clientes do mercado interno

( ) Atendimento da exigência de clientes do mercado externo

\section{Recursos necessários e benefícios gerados}

4) Investimentos realizados para a implantação do programa de melhoria da qualidade:

\begin{tabular}{|l|l|}
\hline Tipos de Investimentos & \% da Receita Total no ano de implantação \\
\hline Aquisição de Máquinas/Equipamentos & \\
\hline Contratação de Consultoria & \\
\hline Treinamento & \\
\hline Alterações na Estrutura Física & \\
\hline Outros (especificar) & \\
\hline
\end{tabular}

5) Custos posteriores à implantação, para manutenção do programa:

\begin{tabular}{|l|l|}
\hline Tipos & $\%$ da Receita Total \\
\hline Pessoal Contratado & \\
\hline Consultoria & \\
\hline Outros (especificar) & \\
\hline
\end{tabular}

6) Marque a alternativa que mais se aplica ao comportamento das variáveis abaixo relacionadas, após a implantação do programa de qualidade:
$5=$ Crescimento superior a $10 \%$
$4=$ Crescimento inferior a $10 \%$
3 = Manteve-se estável
2 = Decréscimo superior a $10 \%$
$1=$ Decréscimo inferior a $10 \%$.

( ) Fatia de mercado

( ) Custos de produção

( ) Vendas

( ) Turnover de empregados

( ) Turnover de clientes

( ) Gastos com publicidade

( ) Gastos com treinamento e capacitação 


\section{Mensuração do Resultado}

7) Qual o grau de importância de se mensurar os efeitos dos resultados proporcionados pelos programas de melhoria da qualidade, no resultado da empresa como um todo?
( ) Muito Importante
( ) Importante
( ) Medianamente Importante
( ) Pouco Importante
( ) Sem importância

8) Atribua notas de 1 a 5 para as razões de se mensurar os resultados proporcionados pelos programas de melhoria da qualidade.

5 = concordo totalmente; 4 = concordo; 3 = não concordo nem discordo; 2 = discordo; 1 = discordo totalmente

( ) Avaliar os programas de qualidade por intermédio de quantificações monetárias

( ) Conhecer quanto a empresa está perdendo por falta de qualidade

( ) Identificar as oportunidades para diminuir a insatisfação do consumidor

( ) Focar esforços de melhoria da qualidade nos itens de maior custo

( ) Alertar para o aparecimento de novos problemas de qualidade

( ) Determinar a viabilidade econômica de um projeto de melhoria da qualidade

( ) Focar esforços de melhoria da qualidade nos itens que mais afetam o nível de satisfação dos clientes

( ) Focar esforços de melhoria da qualidade nos itens que mais afetam a receita

( ) Priorizar a alocação de recursos

( ) Avaliar o desempenho da área responsável pela gestão da qualidade

( ) Determinar o ponto ótimo da alocação de recursos em custos de prevenção e avaliação

9) Atribua notas de 1 a 5 para a fase do processo em que os resultados proporcionados pelos programas de melhoria da qualidade devem ser mensurados:

5 = concordo totalmente; 4 = concordo; 3 = não concordo nem discordo; 2 = discordo; 1=discordo totalmente

( ) No momento em que a empresa está selecionando quais ações irá implementar

( ) Durante a implementação do programa

( ) Após a implementação do programa

10)Atribua notas de 1 a 5 para as ferramentas que a sua empresa utiliza para mensurar os resultados proporcionados pelos programas de melhoria da qualidade.

5 = sempre utilizada; 4 = freqüentemente utilizadas; 3 = medianamente utilizadas; 2 = pouco utilizadas; $1=$ não utilizadas

( ) Apuração do custo de prevenção e avaliação

( ) Apuração do custo com falhas internas

( ) Apuração do custo com falhas externas

( ) Fluxo de caixa descontado das receitas adicionais previstas em função do programa de melhoria da qualidade

( ) Pesquisa de satisfação dos clientes atual e projetada

( ) Percentual da fatia de mercado

( ) Percentual de retenção dos clientes

( ) Percentual de devoluções de vendas e cancelamentos de pedidos

( ) Custos com garantia

( ) Taxas/Custos de sucateamento

( ) Taxas/Custos de retrabalho

( ) Custo financeiro da manutenção de estoques de segurança 
11) Atribua notas de 1 a 5 para as fontes de dados utilizadas para apuração dos resultados.

5 = sempre utilizados; 4 = freqüentemente utilizados; 3 = medianamente utilizados; 2 = pouco utilizados; $1=$ não utilizados

( ) Sistema de contabilidade financeira

( ) Sistema de contabilidade gerencial/custos

( ) Sistemas Operacionais (Estoque, Faturamento, Contas a Receber, etc.)

( ) Pesquisa de mercado

12)Caso apure custos da qualidade, qual sua composição em termos percentuais, nos últimos anos?

\begin{tabular}{|l|l|l|l|}
\hline Tipo & 1999 & 2000 & 2001 \\
\hline Falhas Internas & & & \\
\hline Falhas Externas & & & \\
\hline Prevenção & & & \\
\hline Avaliação & & & \\
\hline Total & $100 \%$ & $100 \%$ & $100 \%$ \\
\hline
\end{tabular}

13)Os resultados obtidos pela empresa com a implantação do programa podem ser considerados:

( ) Satisfatórios

( ) Insatisfatórios

( ) É cedo para afirmar 